\section{Niche breadth and} geographical range: ecological compensation for geographical rarity in rainforest frogs

\author{
Yvette M. Williams $\mathbf{s}^{1,2,3, *}$, Stephen E. Williams ${ }^{1,2,3}$, \\ Ross A. Alford ${ }^{1}$, Michelle Waycott ${ }^{1}$ \\ and Christopher N. Johnson ${ }^{1,2}$ \\ ${ }^{1}$ School of Marine and Tropical Biology, ${ }^{2}$ Rainforest Cooperative \\ Research Centre, and ${ }^{3}$ Centre for Tropical Biodiversity and Climate \\ Change, fames Cook University, Townsville 4811, Australia \\ *Author for correspondence (yvette.williams@jcu.edu.au).
}

We investigated the relationship between diet specialization and geographical range in Cophixalus, a genus of microhylid frogs from the Wet Tropics of northern Queensland, Australia. The geographical ranges of these species vary from a few square kilometres in species restricted to a single mountain top to the entire region for the widespread species. Although macroecological theory predicts that species with broad niches should have the largest geographical ranges, we found the opposite: geographically rare species were diet generalists and widespread species were diet specialists. We argue that this pattern is a product of extinction filtering, whereby geographically rare and therefore extinction-prone species are more likely to persist if they are diet generalists.

Keywords: niche breadth; geographical range; extinction; rarity; diet; ecological specialization

\section{INTRODUCTION}

Brown (1984) argued that species with broad ecological niches should be geographically widespread as well as being locally abundant. This is because a broad niche allows a species to persist in a wide range of different habitat types, while a narrow niche restricts a species to the few places where its niche requirements are met (Gaston 1993; Kunin \& Gaston 1997). Generalists have more areas available to them as suitable habitat and have a correspondingly large potential geographical range (Lawton 1995).

There are two other reasons why we expect geographical range and niche breadth to be positively correlated. First, in geographically restricted species, there is a higher chance that selection will produce ecological specialization as a result of adaptation to local conditions, whereas in widespread species local adaptation is more likely to be frustrated by gene flow from different environments with different selective regimes (Kickpatrick \& Barton 1997). Second, a positive relationship could arise simply as a sampling effect. Widespread species are likely to have access to a more diverse resource base (Gaston et al. 1997). Therefore, measurements of niche breadth should be broader than in geographically restricted species.

However, there is an alternative hypothesis that predicts the opposite pattern. Species with small geographical ranges should have elevated extinction risk, because small ranges make them highly vulnerable to the effects of environmental stochasticity and localized catastrophes (Simberloff 1998; Lawton 1995). Specialists should also be extinction prone because they are sensitive to environmental changes, while generalists are resilient to such changes (Lawton et al. 1994; Johnson 1998). Therefore, the extinction risk due to small geographical range should be compounded in specialists, but compensated in generalists. If geographically rare specialists have high extinction risk, we should find few examples of them, while rare generalists should be better represented in living communities. With increasing geographical range, the risk of extinction declines, so widespread species should persist longer and have more opportunity to evolve specialized adaptations. In this way, selective extinction may create a negative relationship between niche breadth and geographical range. We examined these relationships in microhylid frogs in the genus Cophixalus, from the Wet Tropics of northeast Australia. These species have deep lineages of the order of 10 million years old (Hoskin 2004), with the patterns of distribution and species richness a result of non-random local extinctions related to geographical variation in rainforest stability during the quaternary climate fluctuations (Williams \& Pearson 1997; Graham et al. 2006).

Among living Cophixalus species, there are some with extremely narrow geographical ranges, typically mountain top endemics with ranges as small as $3 \mathrm{~km}^{2}$, compared with $6550 \mathrm{~km}^{2}$ for the most widespread species. They share similar life histories, morphologies and ecologies: all are restricted to rainforest and breed terrestrially, with direct-developing eggs (Hoskin 2004). We suggest that these geographically restricted species have ecological traits that confer resistance to extinction, and here we test if they have broader diets than widespread species.

\section{MATERIAL AND METHODS}

Stomach samples from 86 animals in the collection of the Queensland museum were examined. Of the 11 species of Cophixalus that occur in this region, samples were obtained for 10 . Stomach contents were placed on a gridded sorting tray, viewed under a dissecting microscope, and the abundance of each taxonomic prey group scored to order level. Vegetable matter and rock were recorded in the stomach contents, but not included in the dietary analysis as they were considered to be incidentally ingested. Wherever possible, samples were taken from across the species range; however, no significant difference was found between sites $(p=0.2)$ for dietary evenness. The number of stomach samples used, the number of prey taxa eaten and the geographical range size for each species can be found in table 1. Geographical range size for each species is taken from Williams (2006).

For each frog species, a randomized cumulative curve was constructed for the number of invertebrate taxa occurring against the number of individual stomachs sampled, using the program Species Diversity and Richness v. 2.1 (Henderson \& Sealy 1998). Only frog species in which the curve plateaued were used in this analysis; two species (Cophixalus saxatilus and Cophixalus mcdonaldi) had very few samples for accurate depiction of their diets and were removed. Diet similarity among the species was compared using a multidimensional scaling ordination (MDS) based on the mean abundance of each dietary category across the individuals for each species. We calculated two measures of dietary specialization for each species: (i) an estimate of total dietary richness (Michaelis- 
Table 1. The number of stomach samples examined, the number of invertebrate taxa observed in the diet of each species of Cophixalus, the total geographical range of each species in kilometre and the percent of available rainforest occupied by each species.

\begin{tabular}{lcccc}
\hline species & number of samples & number of taxa eaten & range size $\left(\mathrm{km}^{2}\right)$ & $\begin{array}{l}\text { percentage of rain forest in } \\
\text { region occupied }\end{array}$ \\
\hline C. ornatus & 31 & 10 & 6550 & 66 \\
C. infacetus & 8 & 6 & 3120 & 31 \\
C. aenigma & 23 & 11 & 930 & 9 \\
C. bombiens & 12 & 9 & 695 & 3 \\
C. exiguus & 8 & 7 & 318 & 3 \\
C. hosmeri & 8 & 8 & 300 & $<1$ \\
C. neglectus & 8 & 10 & 37 & $<1$ \\
C. concinnus & 4 & 9 & 3 & 3 \\
\hline
\end{tabular}

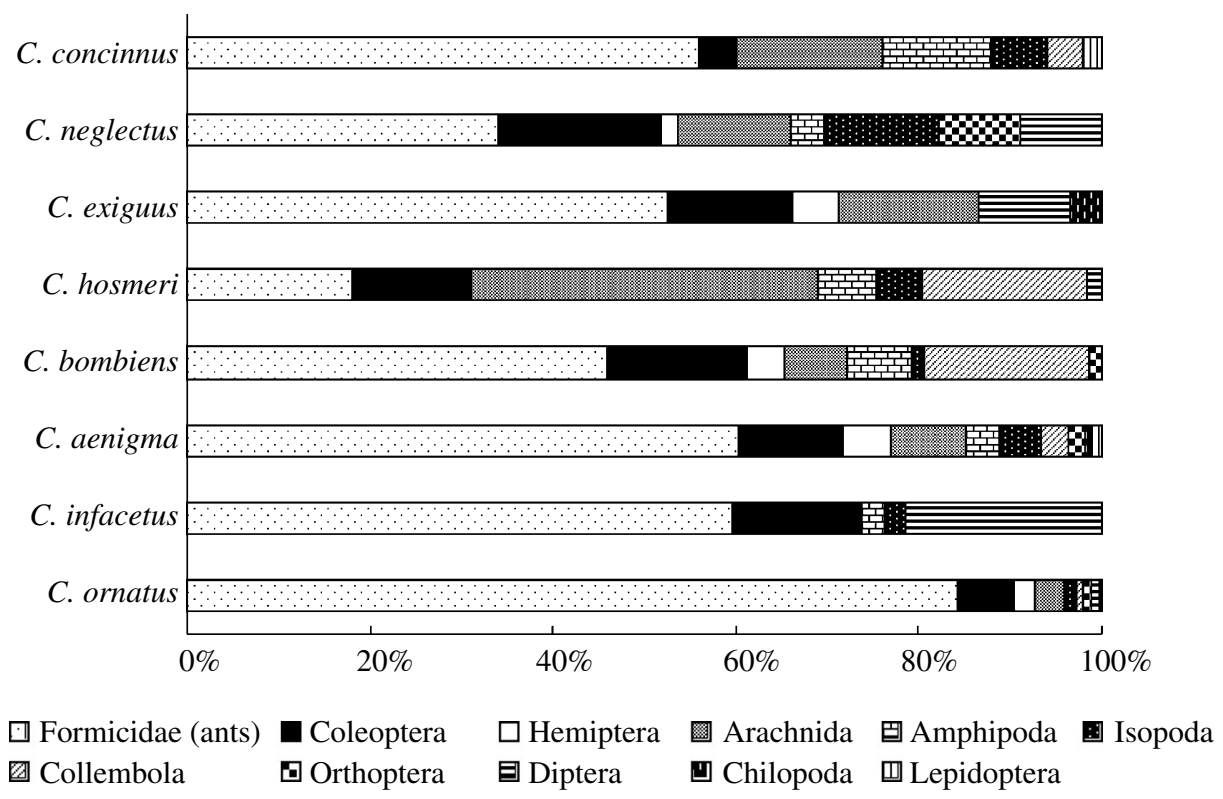

Figure 1. The proportions of each invertebrate taxon consumed by each species of microhylid frog.

Menton estimate of total richness, Raaijmakers 1987) was calculated to account for unequal sample sizes and (ii) a dietary evenness index (Equitability J, Henderson \& Sealy 1998) was calculated from the relative abundance of each invertebrate taxonomic group. Regression analyses were performed to examine the relationships between geographical range size and both measures of dietary specialization. We retested the relationships with phylogenetically independent contrasts, using the program CAIC (Purvis \& Rambaut 1995) and the phylogeny from Hoskin (2004) to control for effects of phylogeny.

\section{RESULTS}

A total of 11 invertebrate taxa were eaten by the eight species of Cophixalus (table 1). Ants represented over $50 \%$ of the stomach contents of five species (figure 1). Patterns of similarity and difference in diets were driven primarily by the abundance of ants in the diet (figure 2) with almost all of this variation (98\%) being represented in the first axis of the ordination. The second MDS axis (figure 2) was related to the proportion of Arachnida and Amphipoda in the diet; however, very little additional variation was explained by this. The species with the most distinctive diet (Cophixalus ornatus) was also the only species whose distribution overlapped substantially with a number of other species (C. infacetus, C. hosmeri, C. neglectus and C. aenigma; Hoskin 2004; Williams 2006).
The total estimated dietary richness was similar across species, with each consuming between 6 and 11 different invertebrate taxa. There was no relationship between range size and dietary richness $\left(r^{2}=0.12, p=0.41\right)$. However, there was a strong negative relationship between the range size and the evenness of the diet (figure $3 ; r^{2}=0.87, p<0.005$; phylogenetically constrained $\left.r^{2}=0.63, p<0.05\right)$. In other words, the geographically restricted species had diets that sampled most broadly from the total range of invertebrate orders eaten by microhylid frogs and with increasing range size, there was an increasing tendency to specialize on one or a few invertebrate orders, in particular, ants (figure 1).

\section{DISCUSSION}

Our analyses show that in this lineage of rainforest frogs, geographically restricted species have the most generalized diets, and widespread species are more specialized. While Gaston et al. (1997) recognized that negative relationships between species range size and niche breadth might occur, they suggested that this would arise owing to sampling in atypical areas. In this study, diets were described from frog samples across the entire range for both restricted and widespread species. Most studies of the relationship of 


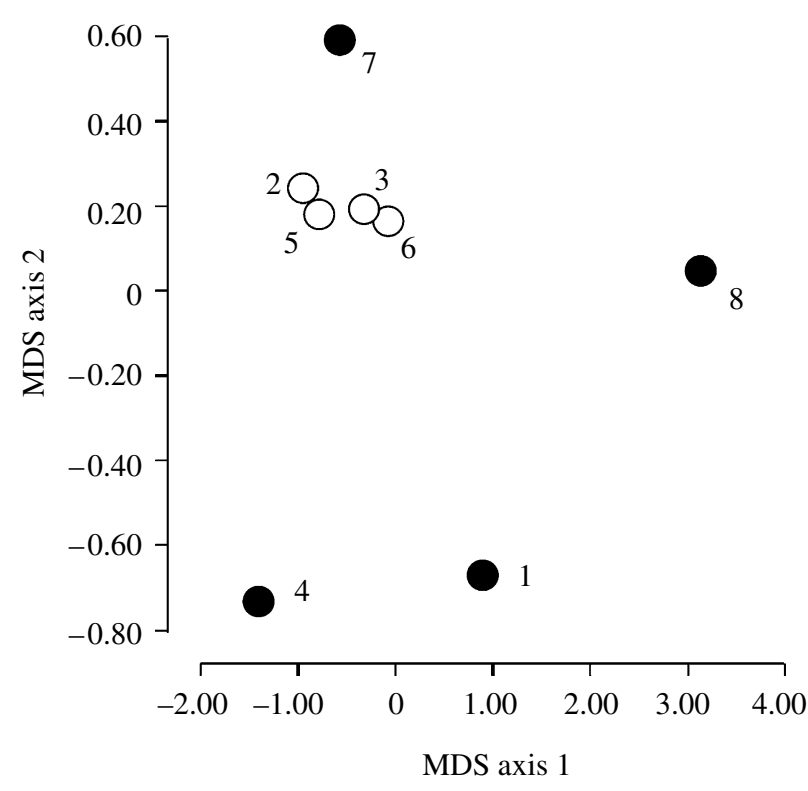

Figure 2. Ordination (multidimensional scaling) using the abundance of different invertebrate taxa in stomach contents of microhylid frogs, to show patterns of similarity in diets. Open circles represent species that rarely overlap in geographical range, filled circles represent species that overlap in geographical range with at least one other species. Species are identified by number as follows: 1, C. concinnus; 2, C. neglectus; 3, C. bombiens; 4, C. hosmeri; 5, C. exiguus; 6, C. aenigma; 7, C. infacetus; 8, C. ornatus.

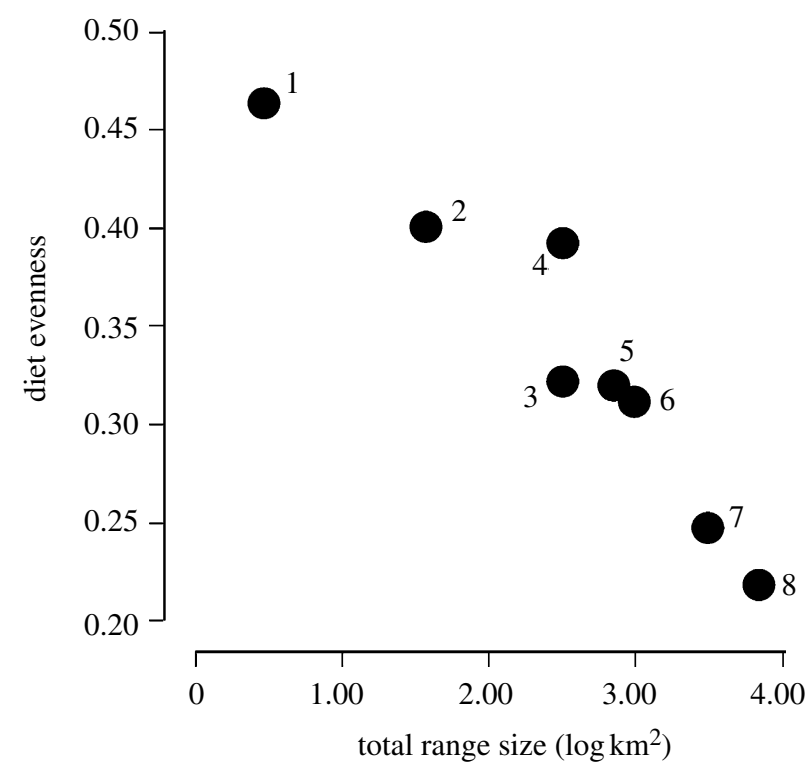

Figure 3. Relationship between dietary specialization (evenness in the relative abundance of invertebrate taxa in stomach contents) and range size for the eight microhylid frog species examined. Species are numbered as in figure 2.

niche breadth to range size have supported 'Brown's hypothesis' (Brown 1984), i.e. species with large range size also have the largest niche or resource breadth. Studies of geographically rare species typically conclude that they are ecologically specialized (Futuyma \& Moreno 1988).

The microhylid frogs of the Wet Tropics have persisted for around $10 \mathrm{Myr}$ (Hoskin 2004), passing through a series of extreme fluctuations in climate (Graham et al. 2006). Widespread species might have persisted through these fluctuations by virtue of their ability to reverse local extinctions by recolonization. However, species restricted to high elevations on a single mountain top do not have this option, and can persist only by virtue of high resilience of local populations. Species that sample broadly from the available range of food should be less susceptible to fluctuations in any particular food type than species that forage in a more specialized way. Pianka (1986) suggested that in low-productivity environments, such as these mountain tops, the low abundance of prey items encourages the generalization of diet to maximize returns per unit effort. This may be the mechanism that forces these geographically restricted species to be dietary generalists in order to survive.

The most widespread species, C. ornatus and C. infacetus, specialized particularly on ants. The reason for specialization on ants is unknown, although they undoubtedly represent a widespread and abundant food source (Andersen \& Majer 2000). Optimal foraging theory (Pyke 1984) suggests that dietary specialization can occur when a reliable and abundant food source is consistently available. It seems plausible that the reliability of ants as a food source across the region has facilitated this level of dietary specialization.

The species with the most geographical overlap with other species was the one with the most distinctive diet, and there was a trend in our data for diet differentiation between species to increase with range overlap. This phenomenon occurs in many taxa (Schoener 1974) including ground-dwelling frogs in Peru, where Toft (1980) showed diet partitioning among 13 sympatric species with overlapping geographical ranges. In the case of Australian rainforest microhylids, the degree of dietary overlap requires further examination in order to determine if diet partitioning is a significant mechanism driving competition and thereby distribution patterns. Dietary partitioning in co-occurring species may also be one of the mechanisms that allow the sympatric species to occur in such high abundances.

In conclusion, our study indicates that 'Brown's hypothesis' is not universally true. In systems where species richness has been shaped by extinction risk, rare and common species may differ greatly in traits that confer ecological resilience on local populations. In the genus Cophixalus, we found that geographically restricted species, which should be at higher risk of extinction, have broad diets, consistent with the hypothesis that broad niche breadth has conferred high ecological resilience on local populations and allowed them to persist. This implies that other more specialized species may once have existed, but those that combined dietary specialization with small geographical range size have gone extinct.

We thank the Queensland Museum, Australia (particularly Patrick Couper, Andrew Amey and Jeanette Covacavich), Phil Munday, Joanne Isaac and Brett Goodman for comments on the manuscript and Glynn Buffett for help in sample collection. This work was supported by the Rainforest Co-operative Research Centre and James Cook University. 
Andersen, A. N. \& Majer, J. D. 2000 The Australian rain forest ant fauna: a biogeographic overview. In Sampling ground dwelling ants: case studies from the world's rain forests (ed. D. Agosti, J. Majer, L. Alonso \& T. Schultz), pp. 51-58. Bulletin No. 18. Perth, Australia: Curtin University of Technology.

Brown, J. H. 1984 On the relationship between abundance and distribution of species. Am. Nat. 124, 255-279. (doi:10.1086/284267)

Futuyma, D. J. \& Moreno, G. 1988 The evolution of ecological specialization. Ann. Rev. Ecol. Syst. 19, 207-233. (doi:10.1146/annurev.es.19.110188.001231)

Gaston, K. J. 1993 Rarity. London, UK: Chapman \& Hall.

Gaston, K. J., Blackburn, T. M. \& Lawton, J. H. 1997 Interspecific abundance-range size relationships: an appraisal of mechanisms. F. Anim. Ecol. 66, 579-601. (doi:10.2307/5951)

Graham, C. H., Moritz, C. \& Williams, S. E. 2006 Habitat history improves prediction of biodiversity in rainforest fauna. Proc. Natl Acad. Sci. USA 103, 632-636. (doi:10. 1073/pnas.0505754103)

Henderson, P. A. \& Sealy, R. M. H. 1998 Program: Species diversity and richness Version 2.1. Pennington, UK: Pisces Conservation Ltd.

Hoskin, C. J. 2004 Australian microhylid frogs (Cophixalus and Austrochaperina): phylogeny, taxonomy, calls, distributions and breeding biology. Aust. F. Zool. 52, 237-269. (doi:10.1071/ZO03056)

Johnson, C. N. 1998 Species extinction and the relationship between distribution and abundance. Nature. 394, 272-274. (doi:10.1038/28385)

Kickpatrick, M. \& Barton, N. H. 1997 Evolution of a species range. Am. Nat. 150, 1-23. (doi:10.1086/286054)

Kunin, W. E. \& Gaston, K. J. 1997 The biology of rarity: causes and consequences of rare- common differences. London, UK: Chapman and Hall.
Lawton, J. H. 1995 Population dynamic principles. In Extinction rates (ed. J. H. Lawton \& R. M. May). New York, NY: Oxford University Press Inc.

Lawton, J. H., Nee, S., Letcher, A. J. \& Harvey, P. H. 1994 Animal distributions: patterns and processes. In Largescale ecology and conservation biology (ed. P. J. Edwards, R. M. May \& N. R. Webb). Oxford, UK: Blackwell Scientific Publications.

Pianka, E. R. 1986 Ecology and natural history of desert lizards. Princeton, NJ: Princeton University Press.

Purvis, A. \& Rambaut, A. 1995 Comparative analysis by independent contrasts (CAIC): an Apple Macintosh application for analysing comparative data. Comput. Appl. Biosci. 11, 247-251.

Pyke, G. 1984 Optimal foraging theory: a critical review. Annu. Rev. Ecol. Syst. 15, 523-575. (doi:10.1146/ annurev.es.15.110184.002515)

Raaijmakers, J. G. W. 1987 Statistical analysis of the Michaelis-Menten equation. Biometrics 43, 793-803. (doi:10.2307/2531533)

Schoener, T. W. 1974 Resource partitioning in ecological communities. Science 185, 27-39.

Simberloff, D. 1998 Small and declining populations. In Conservation science and action (ed. W. J. Sutherland), pp. 116-134. Oxford, UK: Blackwell Scientific Ltd.

Toft, C. A. 1980 Feeding ecology of thirteen syntopic species of anurans in a seasonal tropical environment. Oecologia. 45, 131-141. (doi:10.1007/BF00346717)

Williams, S. E. 2006 Vertebrate distributions and biodiversity in the rainforests of the Australian Wet Tropics. Cooperative Research Centre for Tropical Rainforest Ecology and Management Rainforest CRC, Cairns, Australia. (http//www. rainforest-crc.jcu.edu.au/publications/research\%20reports/ vertebratesAtlas.htm)

Williams, S. E. \& Pearson, R. 1997 Rainforest shape and endemism in Australia's Wet Tropics. Proc. R. Soc. B 264, 709-716. (doi:10.1098/rspb.1997.0101) 